\title{
ОЦЕНКА ЭФФЕКТИВНОСТИ РАЗВИТИЯ ПРОМЫШЛЕННОСТИ И ИННОВАЦИЙ: ОСОБАЯ ЭКОНОМИЧЕСКАЯ ЗОНА (НА ПРИМЕРЕ САНКТ-ПЕТЕРБУРГА)
}

\author{
(c) 2021 Булатова Елена Рашитовна
}

аспирант кафедры экономики и управления предприятиями и производственными комплексами Санкт-Петербургский государственный экономический университет, Россия, Санкт-Петербург E-mail: erb2401@gmail.com

В статье рассмотрены позиции Счетной Палаты Российской Федерации и Министерства Экономического развития Российской Федерации относительно эффективности деятельности особых экономических зон в регионах России. Проанализированы затраты на создание особых экономических зон технико-внедренческого типа и развитие особой экономической зоны в городе СанктПетербург.

Ключевые слова: Особая экономическая зона, Счетная палата Российской Федерации, СанктПетербург, производственные зоны, налоговые преференции, промышленность, инновации.

Особые экономические зоны (ОЭЗ) - один из инструментов реализации промышленной политики стран и регионов, заинтересованных в росте экономики, в том числе ее промышленной составляющей.

Целями создания ОЭЗ является: значительное увеличение экономических показателе в регионах базирования, наращение объемов экспорта, создание новых высокотехнологичных производств, создание новых рабочих мест, развитие инноваций и др.

С течением времени особые экономические зоны как понятие и механизм стали использоваться в широком значении, находя применение к новым отраслям экономической деятельности и начали выделяться отдельные виды экономической деятельности, напрямую не связанные только с промышленностью (как например свободные порты и особая таможенная зона).

Само понятие «особая экономическая зона» стало настолько часто употребляться не только в экономике, но и в обычной жизни людей, что это заслуживает особого внимания, так как далеко не все механизмы поддержки и развития промышленности проходят испытание временем, но и получают настолько широкое распространение.

В Российской практике чаще употребляется понятие «Особая экономическая зона», закрепленное Федеральным законом от 22.07.2005 № 116-Ф3 «Об особых экономических зонах в Российской Федерации», но в литературе можно встретить также понятие «Специальная эко- номическая зона». Второе понятие происходит от дословного перевода с английского «special economic zone (SEZ)».

В нынешнем виде особые экономические зоны берут свое начало в Ирландии в конце 20 века [3]. Свободная портовая зона возникла на территории аэропорта Шеннон. С 1959 г. после объявления правительством страны о создании вблизи аэропорта зоны свободного предпринимательства на территории в 243 га зарегистрировалось более 100 компаний [4]. Согласно Мировому инвестиционному отчету по итогам 2019 года, подготовленному одним из подразделений Генеральной Ассамблеи $\mathrm{OOH}$ - Конференцией ООН по торговле и развитию (ЮНКТАД), в мире насчитывается около 5400 специальных экономических зон в 147 экономиках [16].

В России ОЭЗ могут быть расположены на территории производственных зон в соответствии с Градостроительным кодексом Российской Федерации (ГрК) [1]. Согласно ГрК выделяют производственные зоны, на которых могут быть расположены преимущественно производственные предприятия, склады и т.д.

Ряд ОЭЗ России разделен на площадки, зачастую независимые и находящиеся на значительном расстоянии друг от друга, но находятся в ведении одной управляющей компании, как, например, в Санкт-Петербурге и Республике Башкортостан.

Целью данной работы является выявление необходимости развития территорий производственных зон посредством использования меха- 
низма ОЭЗ на территории России и, в частности, на территории Санкт-Петербурга.

Как было ранее отмечено механизм использования инструмента развития экономики посредством ОЭЗ был запущен в России в 2005 году [2]. На сегодняшний день в России возможно создание 4-х типов ОЭЗ [14]:

- ОЭЗ промышленно-производственного типа, чья основная цель - увеличение производства и переработки товаров в регионе базирования, а также увеличение экспортных показателей (17 созданных и создаваемых ОЭЗ).

- ОЭЗ технико-внедренческого типа, цель развитие инновационной деятельности (7 созданных и создаваемых ОЭЗ).

- ОЭЗ туристско-рекреационного типа, цель - развитие и оказание услуг в сфере туризма (10 созданных и создаваемых ОЭ3).

- Портовые ОЭЗ для организации судостроительной, судоремонтной деятельности, предоставления логистических услуг и создания новых транспортных маршрутов (2 созданных и создаваемых ПОЭЗ).

В период с начала действия закона о создании ОЭЗ в России в 2005 году по 01.11.2019 было создано 37 ОЭЗ на территориях 32 субъектов Российской Федерации [9]. Ликвидировано более 10 ОЭЗ.

Инициатором создания ОЭЗ на территории определенного региона выступает сам субъект России. Разрешение на создание выдает Министерство экономического развития Российской Федерации. ОЭЗ создаются на 49 лет.

Каждая ОЭЗ наделяется особым юридическим статусом, дающим резидентам ОЭЗ налоговые льготы и таможенные преференции, а также обеспечивающим доступ к инженерной, транспортной и деловой инфраструктурам (льготы по налогу на прибыль, налогу на имущество, земельному налогу, пониженные тарифы страховых взносов, применение таможенной процедуры свободной таможенной зоны, льготные ставки арендной платы за пользование объектами недвижимости).

Чтобы стать резидентом ОЭЗ инвестору необходимо соответствовать ряду требований, зависящих от типа ОЭЗ. Наблюдательный совет принимает решение о присвоении статуса резидента инвестору после рассмотрения бизнесплана.

После преодоления 10-летнего рубежа существования первых ОЭЗ в России были подведе- ны итоги их функционирования. В 2016 году на официальном сайте Счетной палаты Российской Федерации (СП) был опубликован результат проверки деятельности ОЭЗ со следующим заголовком «За 10 лет ОЭЗ так и не стали действенным инструментом поддержки экономики» [6].

Проверки были также проведены и в последующие годы. На официальном сайте ведомства опубликованы результаты проверок за 2018, 2019 и 2020 годы.

Отчет СП 2018 года подчеркивает, что по результатам ранее проведенной проверки «за время своего существования особые экономические зоны так и не стали действенным инструментом поддержки национальной экономики, реальный экономический эффект от реализации механизма в виде особых экономических зон не достигнут» [7], за период 2017 года кардинальных изменений нет, несмотря на улучшение ряда показателей эффективности ряда ОЭЗ.

При этом в отчете приводится оценка стоимости создания 1 рабочего места: при учете затраченных бюджетных средств - 7,1 млн. рублей, при учете затраченных бюджетных средств и средств инвесторов - 17,4 млн. рублей.

Отчет СП 2019 года был составлен на основании анализа деятельности ОЭЗ в рамках влияния их деятельности на развитие экспорта [8].

В соответствии с вышеуказанным отчетом анализ поставок готовой продукции по таким позициям как: стекловолокно и продукты из него, шины автомобильные, продукция фармакологии и сборочного производства, чей стоимостной объем составляет свыше $80 \%$ от общего стоимостного объема вывозимой продукции ОЭЗ, показал, что она предназначена прежде всего для реализации на внутреннем рынке страны.

Однако оценка наличия аналогичных производств в России показала значительное количество производственных предприятий, имеющих схожие по своей специфике товары, осуществляющие свою деятельность в обычном режиме, без применения определенных льгот, предусмотренных в рамках ОЭЗ.

Ряд выводов из более ранних отчетов СП был учтен законодательством, однако даже в отчете 2020 года, акцент в котором был отдан проверке результативности применения преференциальных режимов, СП отмечает отсутствие «прорывного влияния ... на экономику России» [10].

Несмотря на результаты отчетов СП разви- 
тие ОЭЗ продолжается. Одной из основных проблем последующего расширения ОЭЗ в России отмечается отсутствие стратегических документов, касающихся создания и функционирования инструментов развития территорий, в том числе особых экономических зон в Российской Федерации, что является причиной непродуманных управленческих решений, приводящих к использованию средств бюджетов разных уровней без достижения запланированного результата.

Несмотря на негативную оценку деятельности ОЭЗ со стороны СП и явно позитивную оценку со стороны Министерства экономического развития Российской Федерации (являющегося куратором и создателем ОЭЗ) единого понимания дальнейшего развития ОЭЗ как инструмента повышения экономических показателей регионов и Российской Федерации на данный момент нет.

Рассмотрим затраты на создание ОЭЗ на примере ОЭЗ технико-внедренческого типа с точки зрения расходов федерального и регионального бюджетов по состоянию на 01.01.2018 (таблица 1). Согласно данным таблицы $10 Э 3$ Москвы и Санкт-Петербурга профинансированы в наибольшей степени из бюджетов регионов базирования.

Рассмотрим подробнее ОЭЗ «Санкт-Петербург». Данная ОЭЗ была создана в 2006 году [на основании Постановления РФ от 21.12.2005 № 780] и по состоянию на 01.01.2021 состоит из двух площадок «Нойдорф» и «Новоорловская».

Участок «Нойдорф» располагается в поселке Стрельна. Площадь участка составляет 19 га. Данный участок ОЭЗ заполнен резидентами на $100 \%$, количество резидентов - 9 .

Участок «Новоорловская» расположен в При- морском районе. Площадь участка составляет 163,33 га. Количество резидентов - 50, свободных земельных участков более 30 га. [12].

Не смотря на наличие свободных земельных участков для привлечения инвесторов в СМИ периодически появляется информация о расширении ОЭЗ Санкт-Петербург. В 2019 году планировалось создание третьей площадки в Ломоносовском районе [13], но все же было принято решение о расширении территории действующего участка ОЭЗ «Новоорловская». Закупка на выполнение работ по строительству объекта: «Инженерная, таможенная, дорожная инфраструктура особой экономической зоны по адресу: Санкт-Петербург, участок территории особой экономической зоны «Новоорловская» была опубликована в феврале 2021 года [11]. В планах города также создание третьей площадки ОЭЗ Санкт-Петербург в производственной зоне «Парнас» [15].

Согласно рейтингу ежегодного издания «Бизнес-навигатор по особым экономическим зонам России - 2020», подготовленному при поддержке Министерства экономического развития Российской Федерации, ОЭЗ в городе Санкт-Петербург заняла 3 место из 6 (в рейтинг включена ОЭЗ «Исток», созданная за счет внебюджетных средств) [5].

На фоне отсутствия единой стратегии создания и функционирования инструментов развития территорий и в том числе относительно стратегии развития ОЭЗ реализация промышленной политики региона посредством данного инструмента достаточно спорна. Согласно данным таблицы 1 создание ОЭЗ затратный для бюджета способ увеличения промышленного и инновационного развития региона. При общей

Таблица 1. Информация об источниках финансирования объектов инфраструктуры на 1 января 2018 года, млн. рублей

\begin{tabular}{|c|c|c|c|c|c|c|}
\hline \multirow[b]{2}{*}{ № } & \multirow{2}{*}{$\begin{array}{c}\text { Наименование } \\
\text { ОЭ3 } \\
\text { (Технико- } \\
\text { внедренческого } \\
\text { типа) }\end{array}$} & \multicolumn{5}{|c|}{ Профинансировано на 01.01.2018 за период строительства } \\
\hline & & Всего & $\begin{array}{c}\text { За счёт средств } \\
\text { федерального } \\
\text { бюджета }\end{array}$ & $\begin{array}{c}\text { За счёт средств } \\
\text { бюджета субъ- } \\
\text { екта РФ }\end{array}$ & $\begin{array}{c}\text { За счет средств } \\
\text { управляющей } \\
\text { компании }\end{array}$ & $\begin{array}{l}\text { За счет вне- } \\
\text { бюджетных } \\
\text { источников }\end{array}$ \\
\hline 1 & 2 & 3 & 4 & 5 & 6 & 7 \\
\hline & ВСЕГО: & 192249,02 & 106754,60 & 69547,98 & 13391,05 & 2555,39 \\
\hline 1 & \begin{tabular}{|l} 
в г. Санкт- \\
Петербурге
\end{tabular} & 16456,10 & 5485,38 & 10437,54 & 533,18 & \\
\hline 2 & в г. Москва & 29737,80 & 10106,24 & 17910,58 & 1720,98 & \\
\hline 3 & в г. Томске & 14107,40 & 8118,16 & 5535,79 & 401,88 & 51,57 \\
\hline 4 & «Дубна» & 11750,55 & 9242,33 & 2184,78 & 323,44 & \\
\hline 5 & «Иннополис» & 24660,43 & 13894,42 & 9135,46 & 38,05 & 1592,50 \\
\hline
\end{tabular}


площади ОЭЗ Санкт-Петербург в 182,33 га по состоянию на 01.01.2018 на создание объектов инфраструктуры израсходовано более 90 млн. рублей на 1 га. Кроме того, стоит учитывать, что формат ОЭЗ обеспечивает своим резидентам преференциальные условия налогообложения и таможенные льготы, что означает значительны выпадающие доходы в федеральный и региональный бюджеты, а также во внебюджетные фонды. Экономическая эффективность деятельности ОЭЗ, фигурирующая в отчетах самих ОЭЗ и Министерства экономического развития Российской Федерации оспаривается в отчете СП за 2020 год: «по ряду ОЭЗ достигнутая благоприятная экономическая динамика имеет характер естественного, неинтенсивного роста в определенных сферах деятельности и обеспечивает комфортные условия функционирования ранее созданных предприятий» [9]. По результатам функционирования ОЭЗ за период почти 15 лет эффективность деятельности не подтверждена. Для Санкт-Петербурга, как для города федерального значения, вопрос эффективности развития производств с точки зрения территориальных возможностей стоит наиболее остро в связи с малой площадью данного субъекта Российской Федерации и необходимостью максимально эффективного использования каждого гектара территорий, предназначенных для промышленности. В связи со значительным превышением доли финансирования создания ОЭЗ бюджетом Санкт-Петербурга в сравнении с федеральным участием (почти в 2 раза) городу необходимо объективно оценивать эффективность использования данного инструмента для привлечения инвесторов. На фоне кризисных явлений последних 20 лет, включающих в себя не только мировые финансовые кризисы, которые возможно спрогнозировать, но и непрогнозируемые кризисы, вызванные пандемией, есть смысл рассмотрения иных способов привлечения инвесторов. Так инженерная подготовка территорий производственных зон без статуса ОЭЗ потребует от города только подготовку земельных участков для будущих инвестиционных проектов, но не потребует от города обеспечения преференциальных мер поддержки инвесторов, а значит обеспечит бюджет субъекта России более значительными налоговыми поступлениями.

\section{Библиографический список}

1. Градостроительный кодекс Российской Федерации (с изменениями на 30 декабря 2020 года) (редакция, действующая с 10 января 2021 года) /Кодекс РФ от 29.12.2004 № 190-ФЗ.

2. Федеральный закон от 22.07.2005 N 116-Ф3 (ред. от 30.12.2020) «Об особых экономических зонах в Российской Федерации» // «Собрание законодательства РФ», 25.07.2005, N 30 (ч. ІІ), ст. 3127.

3. Арская Е.В., КравченкоЛ.Н., УсатоваЛ.В.Этапы возникновения и развития свободных экономических зон // Экономика. Информатика. 2018. № 3. URL: https://cyberleninka.ru/article/n/etapy-vozniknoveniya-irazvitiya-svobodnyh-ekonomicheskih-zon (дата обращения: 13.05.2021).

4. Кузнецова Е.Г.Свободная экономическая зона Шеннон: опыт создания и путь к успеху // Региональная экономика: теория и практика. 2013. № 11. c.58 URL: https://cyberleninka.ru/article/n/svobodnayaekonomicheskaya-zona-shennon-opyt-sozdaniya-i-put-k-uspehu (дата обращения: 13.05.2021).

5. Бизнес-навигатор по особым экономическим зонам России, 2020. Выпуск 4 / А.Н.Андреев, М. М.Бухарова, Л.В.Данилов, В.И.Зверков, Е.А.Кашинова, Е.И.Кравченко, М.А.Лабудин, М.А.Махаева, А.В.Телеба, А.Г.Шипугин, А.В.Шпиленко; редакционная коллегия: А.В.Шпиленко (ответственный редактор), В.И.Зверков, А.Н. Козловский; Ассоциация развития кластеров и технопарков России.- Москва: АКИТ РФ, 2020. - 203 с.: ил. - ISBN 978-5-6044817-1-4:1500 экз.

6. За 10 лет ОЭЗ так и не стали действенным инструментом поддержки экономики // [Электронный ресурс] Официальный сайт Счетной палаты / [сайт]. [2016]. URL: https://ach.gov.ru/checks/9903 (дата обращения: 06.05.2021).

7. Отчет о результатах экспертно-аналитического мероприятия «Мониторинг эффективности использования бюджетных ассигнований федерального бюджета при создании и функционировании в 2017 году особых экономических зон, созданных в соответствии с Федеральным законом от 22 июля 2005 года № 116-Ф3 «Об особых экономических зонах в Российской Федерации» // [Электронный ресурс] Официальный сайт Счетной палаты / [сайт]. [2018]. URL: https://ach.gov.ru/checks/9786 (дата обращения: 06.05.2021), с. 40. 
8. Отчет о результатах экспертно-аналитического мероприятия «Анализ номенклатуры и объема товаров, ввозимых на территории особых экономических зон и вывозимых с таких территорий в 2016-2017 годах» // [Электронный ресурс] Официальный сайт Счетной палаты / [сайт]. [2019]. URL: https://ach.gov.ru/ checks/9695 (дата обращения: 06.05.2021).

9. Отчет о результатах экспертно-аналитического мероприятия «Анализ практики применения преференциальных режимов, действующих на территории Российской Федерации, с точки зрения их влияния на экономический рост и соответствия заявленным целям» // [Электронный ресурс] Официальный сайт Счетной палаты / [сайт]. [2020]. Систем. требования: Adobe Acrobat Reader. - URL: https://ach.gov.ru/checks/10441 (дата обращения: 06.05.2021).

10. СП не увидела прорывного влияния преференциальных режимов на экономику России // [Электронный ресурс] Официальный сайт Счетной палаты / [сайт]. [2020]. URL: https://ach.gov.ru/checks/10441 (дата обращения: 07.05.2021).

11. Извещение о закупке № 32109880741 [Электронный ресурс] // ЕДИНАЯ ИНФОРМАЦИОННАЯ СИСТЕMА В СФЕРЕ ЗАКУПОК/ - URL: https://zakupki.gov.ru/223/purchase/public/purchase/info/common-info. html?regNumber=32109880741 (дата обращения: 03.05.2021).

12. Инфраструктура особой экономической зоны [Электронный ресурс] // OЭ3 «Санкт-Петербург» URL: https:// www.spbsez.ru/infrastructure/ (дата обращения: 01.05.2021).

13. Минэкономразвития одобрит расширение особой экономической зоны Санкт-Петербург (06.06.2019) [Электронный ресурс] // ИД «Коммерсантъ» URL: https://www.kommersant.ru/doc/3992456 (дата обращения: 01.05.2021).

14. Особые экономические зоны [Электронный ресурс] // Официальный сайт Министерства экономического развития Российской Федерации URL: https:/www.economy.gov.ru/material/directions/regionalnoe_razvitie/ instrumenty_razvitiya_territoriy/osobye_ekonomicheskie_zony/ (дата обращения: 01.05.2021).

15. ОЭЗ «Санкт-Петербург» получит площадку в промзоне «Парнас» (08.04.2021) [Электронный ресурс] // ИД «Коммерсантъ» URL: https://www.kommersant.ru/doc/4763060 (дата обращения: 01.05.2021).

16. World Investment Report 2019. Chapter IV: Special Economic Zones [Электронный ресурс] // United Nations Conference on Trade and Development.- 2019.- Систем. требования: Adobe Acrobat Reader.- URL: https:// unctad.org/webflyer/world-investment-report-2019. 